\title{
On the Current Situation and Development Trend of National Cross-border Education
}

\author{
Shui-ping HUANG ${ }^{1, *}$ \\ ${ }^{1}$ Guangdong University of Science \& Technology, Dongguan, Guangdong, China. \\ ${ }^{*}$ Corresponding author
}

Keywords: Cross-border education, Current situation, Strategies, Trend.

\begin{abstract}
Meeting the economical globalization, the development of national cross-border education is vibrant. The study on current cross-border education development like sino-foreign cooperation in running schools, running school oversea and mutual studying abroad will provide active enlightenment for forecasting of national cross-border education development trend and planning of cross-border education development strategies.
\end{abstract}

\section{Introduction}

With the deepening of globalization and changing of new technology revolution, the traditional education concept has been replaced by new educational ideas that intercultural communication and international understanding become the new task of education, and the protection and optimization of common interests of human-beings turn the common topic and responsibility of global education. Therefore, it becomes a new education task that cultivating a branch of international talents with international visions, familiar with international culture and rules, and adept in international exchange and collaboration.

Under the background of globalization, and especially since 30 years of rapid economic development of China, the national education calls for more forms and higher quality, so diverse forms of cross-border education are booming in China. China is gradually becoming the main importing country of cross-border education and meanwhile joining in the exporting country. The main forms of cross-border education contain sino-foreign cooperation in running schools, running school oversea, mutual studying abroad, joint research, employing foreign teachers, and student exchange, which turns important parts of international collaboration and exchange of education. It also plays an active role in enhancing the reform of national education system, widening the talent cultivation road, meeting the need of national education development and Chinese people's demand for diversified education and promoting the opening of education.

\section{Current Situation of Sino-foreign Cooperation in Running Schools}

\section{Rapid Development of Sino-foreign Cooperation in Running Schools}

Since the Sino-foreign Cooperation in Running Schools Regulations issued in 2003, after a decade's development, China's sino-foreign cooperation in running schools has formed and maintained a high-level and rapid momentum, received growing social attention, reputation and influences. 
So far, there are 2056 partner universities, secondary institutions and programs in total, including 7 universities with partnerships, like Shanghai New York University, Ningbo Nottingham University, Xi'an Jiaotong-Liverpool University, 49 secondary institutions which are undergraduate or higher, and 852 programs. Sino-foreign cooperation in running schools covers various levels and forms, including 12 disciplines which are science, engineering, agriculture, medicine, human culture and social science, etc, and over 200 programs. From the perspective of running scale, and according to incomplete statistics, there are 550 thousand students enrolled at sino-foreign collaboration institutions, among which 450 thousand are at higher education stage, accounting for $1.4 \%$ of the full-time enrolled students at higher school. And the number of graduates at the higher education stage of the sino-foreign collaboration institutions exceeds 1.5 million. Moreover, near 400 high schools in 25 countries like US, UK and Australia carried out educational collaboration with institutions in China.

\section{Sino-foreign Cooperation in Running Schools Is Facing a New Trend and New Normal Status}

In the past decades, the introducing of advanced foreign educational beliefs, educational contents, teaching methods, talent cultivation modes and management experiences, promotes the national disciplines and program construction, cultivation of teachers and internationalized talents, strengthens education vigor, enhances education and teaching reform, and obtains some achievement.

Presently, the adjustment of national development strategies and constantly changing background of international situation provides new historical opportunities for improving the quality of sino-foreign cooperation in running schools. The administrators of the collaborative institutions should make well top-level design and strategic planning, complete laws and regulations, and coordinate sino-foreign cooperation in running schools, studying in China and running school oversea.

Firstly, China should shift focus from scale expansion to quality improvement. Now there are nearly 600 high schools and institutions carrying out sino-foreign collaborative programs in China. With the development of Chinese education, sino-foreign cooperation in running schools should fully play its role in improving school teaching force and internationalized levels. And China should strengthen the construction of quality guarantee system of sino-foreign cooperation in running schools, regularly carry out the quality evaluation work, standardize the running order, increase the construction of penalty and withdrawal mechanism, and eliminate the institutions which don't meet the legal requirements and commit the cooperation agreements.

Secondly, China should shift the focus from learning to innovating. In the initial stage, sino-foreign cooperation of running schools proposed studying at home countries, and puts the focus on students' need of studying abroad and market performances of joint programs instead of disciplines construction and coverage. Now in the new stage of innovation-driven and transformational development, the society proposes sino-foreign cooperation of running schools new requirements that Chinese tertiary institutions should own the advanced awareness, basis and abilities, avoid short-term running and focus on discipline construction and talent cultivation to create first-class education rooted in China. Moreover, By fully playing the leading role of sino-foreign cooperation of running schools, Chinese tertiary institutions can innovate the running mechanism mode, establish new international schools, play the "catfish effect" and enhance the national education reform. 
Thirdly, shift from introducing oversea resources in bulk to focus on excellent resources and put strict standards on exporting resources. Recently, considering the major layout of the introduced programs and institutions, it's possible that to carry out cooperation of running schools mainly in natural science fields like science, engineering, agriculture, and medicine, and fields covering advanced manufacturing, modern agriculture and emerging industries. It's essential to put strict control on foreign high schools running chain schools and ensure the educational quality.

Fourthly, change the management focus from administrative approval to strengthen process supervision, top design and policies making, and optimize management ways. Presently China's Ministry of Education has developed and run the systems online such as the application system, evaluation system and annual reporting system of sino-foreign cooperation of running schools, gradually realized "online application" and "one stop" approval mechanism, and almost accomplished the information management of sino-foreign cooperation of running schools.

\section{Current Situation of Running Schools Oversea}

Chinese tertiary institutions running schools oversea is an important step of exporting Chinese education and important part of Chinese cross-border education.

\section{Running Schools Oversea Initially Takes Shape}

Since 1970s, Chinese tertiary institutions began to explore running schools oversea. As China's comprehensive force strengthens and education's internationalization deepens, the enthusiasm of Chinese tertiary institutions on running schools oversea significantly increases. In recent years, more and more countries invite Chinese tertiary institutions to run branches in local campus or cooperatively run schools. Meanwhile, more and more Chinese tertiary institutions propose the plan of running schools oversea and some have already carried out some educational activities oversea. So far, Chinese tertiary institutions have held three overseas educational institutions and 97 programs, located in 14 countries and regions. Running schools oversea has become a new important aspect of international education for Chinese high schools, and also important measures of improving the level of internationalization, which indicates that the development mode and achievement of Chinese higher education begins to be recognized by the international society.

\section{Running Schools Oversea Are Now Facing a Valuable Historical Opportunity of Development}

On the one hand, the rapid development of Chinese economy and society and expansion of national influences provides an excellent environment for Chinese tertiary institutions running schools oversea. The strengthening of national comprehensive forces provides strong resources support for Chinese tertiary institutions running schools oversea. Meanwhile, National strategies like "One Belt, One Road" make each country's demand for Chinese tertiary institutions running schools oversea growing, which creates a more friendly external environment.

On the other hand, the exporting of economy and culture is speeding up. Presently, China is the second largest economy country of the world, thus more and more countries are eager to know more about China and join in the fast development of Chinese economy. At the same time, a branch of Chinese enterprises are participating in the worldwide economical and trade collaboration outside of China. So Chinese tertiary 
institutions running schools oversea can cultivate talents who know about China and are proficient in professional technology for other countries.

\section{The Stable Strengthening of Chinese Higher Education's Competitiveness Lays Solid Foundation for Chinese Tertiary Institutions Running Schools Oversea.}

Recently, Laos, Jordon and Egypt have proposed that China should run schools in their home countries. The officer of Lao's Ministry of Education claims that Chinese higher education has made substantial progress and hope Chinese universities run educational institutions at Laos and set up more vocational programs which they believe is beneficial for students' employment. Jordon's Ministry of Education and high schools clearly proposed that they would like to follow Chinese mode, run applied technology oriented university with China, carry out multifield engineering technology education and cultivate applied technical talents. Recently, Tanzania and other countries express their willing that China can run an Agricultural University in their countries. Such demand for China running schools at these countries reflects the competitiveness of China's higher education, which lays solid foundation for Chinese tertiary institutions running schools oversea.

\section{Developing Strategies of Running Schools Oversea}

According to the analysis of achievements, weaknesses and future trend of some oversea programs and institutions, it can be seen that running schools oversea play an active role in improving the competitiveness of Chinese higher education. However, running schools oversea are at the initial development stage, so there exists lots of weakness on strategy planning, school ability construction, etc, which requires more efforts and full preparations.

Firstly, from the perspective of strategy and long-term development, China should strengthen strategy support and system innovation of running schools oversea. Chinese tertiary institutions have not run schools oversea for long and without sufficient experiences. So they need strategic plan and unified arrangement, especially on how to coordinate various resources like education, culture, trade and foreign aids in the national strategic framework.

Secondly, China should grasp the strategic opportunity of running schools oversea and actively promote the applied technology education abroad. With the common task of economy development, most developing countries hope to follow Chinese experiences, introduce Chinese applied technical education mode and resources, and cultivate local engineering technical persons to improve local industrialized levels. Under such background, Chinese tertiary institutions should combine its advantages and foreign demands, make careful planning and scientific design, and explore oversea education modes fit for each party's interests.

Thirdly, China should strengthen the ability construction of higher schools to meet the need of market and strategies. Until now, Chinese high schools badly lack internationalized compound talents in general. So how to organize a professional teaching team who are proficient in their profession and master foreign languages is an emphasis of running schools oversea.

Fourthly, China should actively promote educational institutions with high levels to run schools oversea. Chinese high schools running school oversea matters the international fame and influences of Chinese higher education, especially the educational qualities and activities have a direct effect on the international status and influences. So the quality of running schools oversea needs special attention and 
standard. On the one hand, high schools oversea must keep the teaching standard of home schools and cannot issue unequivalent academic diploma, avoiding becoming the "diploma factory". On the other hand, Chinese tertiary institutions running schools oversea should be categorized into the high schools quality evaluation system so as to guarantee the educational quality.

\section{Flow of International Students}

Studying abroad and studying in China are vital components of Chinese opening education to the world and also one of the important fields of Chinese cross-border education.

\section{The Scale of Studying Abroad and Studying in China}

In 1978, the first batch of government sponsored students, 52 in total, went to the US for study, and the number of students and the course choices are very limited. Now the situation of studying abroad changes greatly. In 2014, 459.8 thousand students go abroad for study, nearly covering all the professions and fields.

With the development of national economy and increasing of nation force, there emerges a hot of studying in China: from the year 1950 to 1978, the number of people coming to China for study changes from 33 to 1236, and in 2014, it turns to 377 thousand.

The major choices change from language learning in 1950 to almost all the disciplines, and school choices changes from only a few universities like Tsinghua University and Peking University to over 700 universities.

\section{Studying Abroad or Studying in China Is Beneficial for China's Modernization Construction.}

Through studying abroad, a batch of talents with intercultural communication abilities, innovation abilities and international visions are cultivated for economical and social development. At present, over $70 \%$ of presidents of 985 universities, more than $80 \%$ of academicians of Chinese Academy of Sciences and Academy of Engineering, and over 90\% of the Yangzi River Scholars have the oversea studying experiences.

Studying abroad expands the international influences of China and promotes the Chinese and foreign cultural exchanges. Through studying abroad, students make China contact with the world, and build the communication bridge between Chinese people and the world.

\section{Studying Abroad or Studying in China Face Challenges and Opportunity.}

From the developing perspective, studying abroad is facing a series of challenge. In the first place, the studying abroad policies and regulations need to be completed, for some of which can no longer adapt to new situation and solve new problems. The second challenge is to solve problems in studying abroad and studying in China like personal security, study disputes, legal rights damaged, etc. The third challenge is that the management and serving abilities of oversea study need further improvement.

Chinese tertiary institutions need do the following work to stably push ahead studying abroad and study in China.

Firstly, Chinese tertiary institutions should put equal emphasis on scale enlarging and quality improving. Studying abroad and study in China complement each other, both of which are effective ways of cultivating international talents with high levels. Chinese tertiary institutions should select and guide excellent teenagers to study in world-class 
university so as to cultivate talents that meet the need of reform and development. Chinese tertiary institutions should also encourage and attract worldwide teenagers to study in Chinese higher schools and make studying in China become the pursuit and dream of the ambitious teenagers of the world.

Secondly, Chinese tertiary institutions should perfect systems and regulations of oversea study program, build a complete management and service system of oversea study and construct an overall policy support for oversea study to better guide, regulate and serve oversea study program.

Thirdly, Chinese tertiary institutions should construct talents storage and play its leading role in innovation, entrepreneurship and cultural exchange. They should also encourage students studying abroad to focus on key fields of national economy and society development, frontier of world technology reform and to participate in the innovation-driven development.

Last but not least, Chinese tertiary institutions need comprehensively improve the management and service level of studying abroad and studying in China through information measures, and coordinate the present management system and network information resources to establish a information system devoting to oversee study work.

\section{Summary}

Cross-border education is at the beginning of development in China. For Chinese tertiary institutions, it's both an opportunity and a challenge that they carry out cross-border education. In this process, Chinese tertiary institutions must fully make use of its advantages, actively learn experiences of foreign cross-border education and cultivate a batch of talents with high qualities and international visions to contribute for Chinese economy and society development.

\section{Acknowledgement}

This thesis is the research fruit of provincial key Project -A Study on Sino-foreign Collaboration in Running Schools and its Developing Strategies in Guangdong Province (Project Number: GDJY-2015-C-a004) which is initiated by Guangdong Education Institute.

\section{References}

[1] Zhu Guangqian, Form Evolvement, Classification of Transnational Education and its Enlightenments, Chinese Adult Education, vol.17, p10-12, 2013.

[2] Li Chunyang \& FangYaqiong, Review on National Studies of Cross-border Education in Recent 10 Years, Journal of Jilin Radio and TV University, vol.12, p1-2, 2013.

[3] Wang Lu, Review on Foreign Studies of Cross-border Education in Recent 10 Years, Modern Education Management, vol.12, p118-123, 2014.

[4] Shi Yunyu, Jiangsu Higher Education Service Overseas: Status quo, Global Situation and Countermeasures, Journal of Yangzhou University, vol.6, p7-11, 2013.

[5] He Zhonghui, On Current Study of Sino-foreign Cooperation in Running Schools and Sustainable Development, Vocation, vol.14, p27-28, 2015. 